\title{
Patterns of illness
}

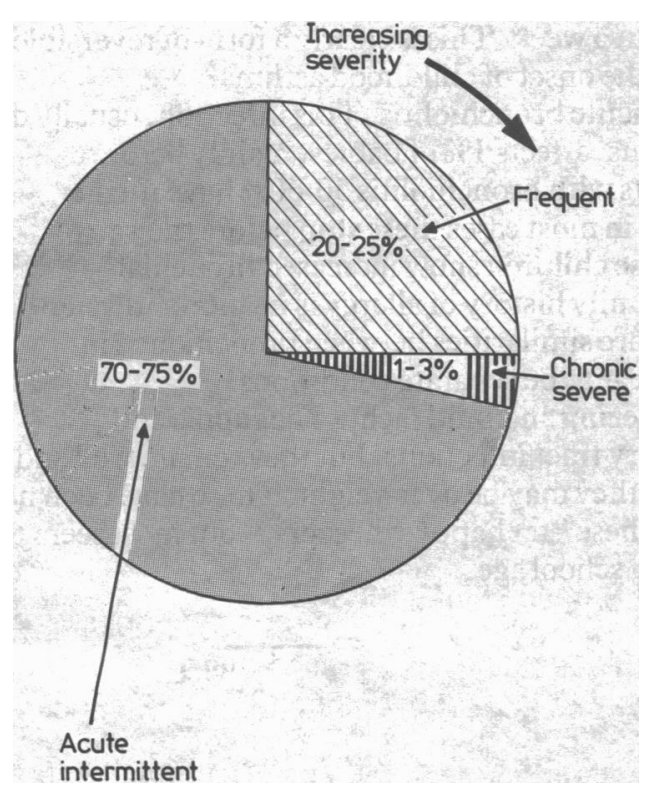

Broadly speaking asthmatic children can be divided into three groups; the divisions are artificial but provide a useful guide to management.

About three quarters have infrequent acute episodes of wheezing, usually associated with signs of viral upper respiratory infection. The episodes vary in duration and severity but lung function returns completely to normal between attacks. Eighty per cent of these children will stop wheezing before adulthood.

Just under a quarter of asthmatic children have more frequent and prolonged wheezing triggered by infective, allergic, emotional, and physical stimuli. Their asthma often starts with similar symptoms to those of the first group but at a younger age. In most of these children sensitive indices of airflow obstruction, such as those derived from a maximum expiratory flow volume curve, are abnormal between attacks, though the peak flow may return to normal.

A third small group, $1-3 \%$ of children with asthma, have severe wheezing which continues throughout childhood. Four out of 5 are boys, symptoms start before the age of 2 , and many also have eczema and rhinitis. There is usually a strong family history of atopy. These children tend to be small and thin and to develop chest deformities. All have abnormal lung function between attacks and most continue to wheeze as adults.

A few, generally older children with grass pollen allergy, wheeze predominantly from May to July. Most asthmatic children, however, have more trouble in the winter months. This is probably because viral respiratory tract infections are more common in winter and because exercise induced asthma is more likely to develop outdoors in cold weather.

Dr John Price, MRCP, is consultant paediatrician, King's College Hospital, London.

\section{Clinical Algorithms}

\section{Incoordination}

\author{
KENNETH C McHARDY
}

The algorithm addresses the problem of diagnosis in a patient whose presentation may range from unsteadiness of gait, through minor clumsiness with, for example, crockery, to a distinct inability to perform fine motor tasks smoothly and efficiently. Some possible underlying problems, such as dizziness or tremor, are dealt with elsewhere in this series. In view of the increasing prevalence of alcohol abuse, acute and chronic disorders related to alcohol consumption and presenting with incoordination are increasingly likely to be met. Drug treatment is also a potentially common cause, particularly with the vast quantities of long acting benzodiazepine hypnotics, such as nitrazepam and flurazepam, prescribed to elderly

Royal Infirmary, Aberdeen AB9 2ZB

KENNETH C MCHARDY, MB, MRCP, medical registrar people. With its propensity to affect the cerebellum and its connections the features of multiple sclerosis should also be sought. Finally, previously undetected myxoedema, which occasionally presents with incoordination as a major symptom, is rewarding to diagnose and treat.

I thank Dr M J Jamieson for his helpful criticism during the preparation of this algorithm.

\section{Further reading}

Critchley EMR, Matthews B, eds. Medicine International 1983;1:1387-525.

Walton JN. Brain's diseases of the nervous system. 8th ed. Oxford: Oxford Medical Publications, 1977.

Beck ER, Francis JL, Souhami RL. Tutorials in differential diagnosis. London: Pitman Medical, 1974. 


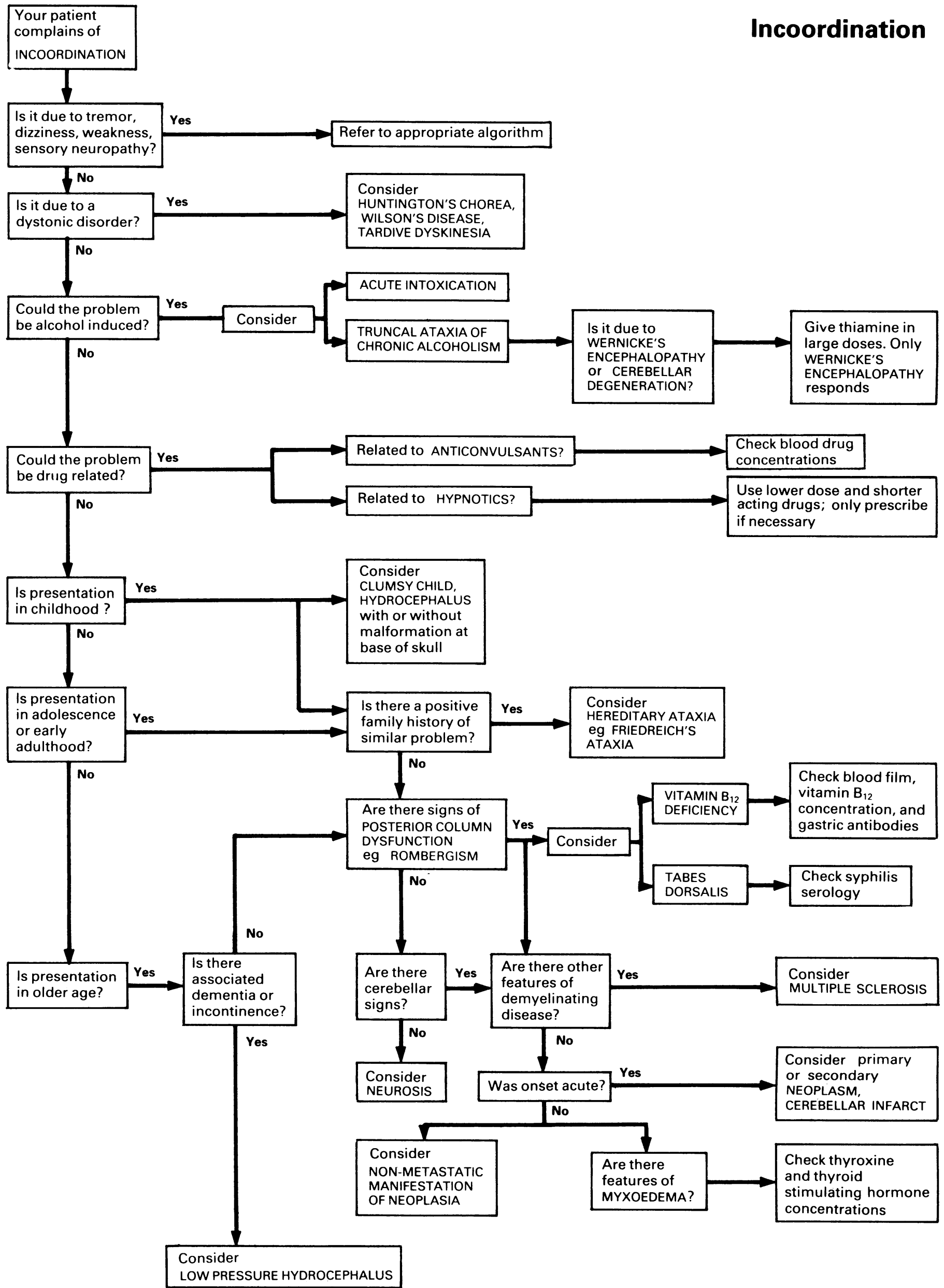

